"Other matters-as to the position and powers of the inspectors, etc., and legal amendments to existing Act, as discussed at the Summer Meeting of the Division at Downpatrick in 1918-might also be included in a Bill.

"It would seem to me, in any event, that it is the clear duty of this Division to formulate a constructive policy of action in all these matters, in the event of any legislative measures which may be proposed later. Any such policy should be well considered.

"I would appeal to the members to treat the matter from a broad, unselfish standpoint, keeping only in view as a goal whatever is in the best interests of the afflicted insane."

A full discussion followed Dr. Nolan's opening statement, in which almost all the members present took part. It seemed to be the general feeling that a strong central controlling body co-ordinating the Irish Asylum Service in the interests of the insane and standardising and improving the treatment and general management of asylums was urgently needed, and should be incorporated into any legislative measure dealing with the same. The various points of Dr. Nolan's paper were discussed and generally approved of. It was finally proposed by Dr. Donelan, seconded by Dr. Gavin and passed unanimously :

"That the Parliamentary Sub-Committee of the Irish Division be directed to consider matters relating to the central control of the asylum service and any cognate matters, and to furnish a report to the Irish Division at its next meeting, and that the names of Dr. Colles, Dr. Greene and Dr. O'Doherty be added to the Irish Division's Parliamentary Sub-Committee."

The Hon. Secretary mentioned that Dr. Eustace kindly invited the Division to hold its Spring Meeting at Hampstead House. Dr. Eustace's invitation was accepted with thanks.

\title{
NORTHERN AND MIDLAND DIVISION
}

The Autumn Meeting of the Northern and Midland Division was held by the kind invitation of Dr. A. J. Eades at the North Riding Asylum, Clifton, York, on Thursday, October 3oth, 1919.

The President, Dr. Bedford Pierce, presided.

The following fourteen members were present: Drs. G. L. Brunton, A. J. Eades, S. Edgerley, C. L. Hopkins, G. R. Jeffrey, W. S. Kay, R. M. Ladell, H. J. Mackenzie, H. D. MacPhail, J. Middlemass, J. E. Middlemiss, B. Pierce, J. B. Tighe, T.S. Adair ; and three visitors-Drs. H. J. Drake-Brockman, J. Lowther and L. R. Oswald (Scottish Division).

Apologies for non-attendance were received from several members.

The minutes of the last meeting were read and confirmed.

A ballot was taken for Henry George Drake-Brockman, M.R.C.S.Eng., L.R.C.P.Lond., Assistant Medical Officer, the Mental Hospital, Middlesbrough. Proposed by Drs. Geddes, Hopkins and Adair as an ordinary member of the Association, and he was unanimously elected.

On the proposal of Dr. Eades, seconded by Dr. Middlemass, Drs. S. R. MacPhail and Bedford Pierce and Major Street were unanimously re-elected to form the Divisional Committee for the next twelve months.

\section{Contribution.}

Dr. G. Rutherford Jefrerey then read a paper entitled "Notes on Three Cases, showing the Value of Hypnosis and Suggestion as an Aid to Treatment." The first case was that of a lady who was suffering "presumably from mania associated with gestation." She broke down mentally from worry and was very restless and exalted. She was hypersensitive, and as her condition "was only a passing emotional storm " it was thought it might be checked if her mind could be " completely calmed." She was put under a light hypnosis and it was suggested to her that she "would sleep all right and awaken feeling well." She slept for nine hours and awoke feeling much better. From this time she steadily improved and made a good recovery. The second case was one in which a distressing 
symptom, vis., the "most frightful desire to injure his wife and children," was made to disappear by suggestion with the aid of hypnosis. Though the patient, who was neurasthenic and depressed, was not cured, he entirely lost the idea, and, indeed, would hardly believe that it had ever existed. The third case was one of neurasthenia and shell-shock in an officer who had on two occasions been blown up and buried. He fell in love with a girl, and after behaving rudely to her mother was told that the parents did not wish to have anything more to do with him. This worried him and "aggravated all his neurasthenic symptoms." He could not bring himself, however, to write and apologise and accept the decision. He was put to sleep under a light hypnosis and a suggestion was made to him that he should write. On awakening he immediately put this into effect before attempting to do anything else. After this he certainly improved.

The first case is really one of "marked emotionalism," and shows how the patient's mind righted itself after being put into a "condition of blank and calm." The second shows how a distressing obsession can be got rid of, and the third indicates that a "persistent 'aboulia ' causing a more or less severe mental paresis" can be abolished by suggestion. Dr. Jeffrey says that, from his experience, he is "convinced that hypnosis and suggestion treatment have an important therapeutic place in the treatment of the psycho-neuroses," and that "given a suitable case it is worthy of trial."

An interesting discussion followed, in which most of the members present took part.

Dr. Pierce made some reference to forthcoming changes in lunacy administration, and this was followed by a talk about the nursing examination and the effect that the altered conditions of asylum work might have upon it.

The following resolution was then proposed by Dr. Middremass, seconded, and unanimously carried, that "in the opinion of the Northern and Midland Division of the Medico-Psychological Association the question of the revision of the Handbook should now be considered by the Education Committee with a view to its improvement in certain parts; at the same time this Division is of opinion that the present standard of teaching and of the examination for the nursing certificate of the Association should not be reduced."

A very interesting and enjoyable meeting was brought to a close, a hearty vote of thanks having been accorded to Dr. Eades for his kind hospitality.

\section{SOUTH-WESTERN DIVISION.}

The Autumn Meeting of the above Division was held at University College, Bristol, on Friday, October 24th, 1919, at 2 p.m.

The following members were present : Drs. Brown, Devine, Eager, Lavers, Mules, MacBryan, Nelis, Soutar and Thomas, and the Hon. Divisional Secretary (Dr. Bartlett).

Dr. Soutar was voted to the Chair.

Letters of regret for non-attendance from Drs. Aveline and MacDonald were read.

Dr. Bartlett was nominated as Hon. Divisional Secretary.

Drs. MacBryan and Soutar were nominated Representative Members of Council. Dr. Devine very kindly extended an invitation to the Division to meet at the Portsmouth Mental Hospital, April 23rd, 1920.

The Chairman alluded to the loss the Association had sustained in the recent deaths of Dr. Mercier, Dr. Drapes and Dr. Wiglesworth, which were all recorded with deep regret by all members present.

Dr. Eager then read his paper on "Head Injuries in Relation to the Psychoses and the Psycho-neuroses."

The Chairman expressed the unanimous appreciation by the audience of the able work of Dr. Eager in this valuable record of the after-effects of head injuries.

Drs. Soutar, Devine, Lavers and Bartlett joined in the ensuing discussion. 